\title{
MENYONGSONG 25 TAHUN SISTER CITY JAKARTA - TOKYO
}

\author{
Witarsa Tambunan
}

\begin{abstract}
The term sister city was originally introduced by Dwight Eisehower to the XII century, which means the town brothers, friendly city. The concept of sister city intends to maximize the relationship between community members in all corners of the world to be created and maintain peace. Sister city Jakarta - Tokyo has succeeded in building a positive image of Jakarta as an international city. As an international city, Jakarta has a vision of "Aligning the city of Jakarta with cities abroad." That is why the cooperation program of sister city Jakarta - Tokyo for the Jakarta Provincial Government is a necessity as a consequence of Jakarta as the Capital of Indonesia Republic and international city. In making the city of Jakarta as the city of city services, through its sister city Quezon City - Tokyo, Jakarta Provincial Government to send its agents (HR) to Tokyo to follow the Exchange Program, Apprenticeship and Training Apparatus, to turns knowledge, skill, and attitude toward positive changing of apparatus, it means improved the quality of human resources so that its services meet international standards so the city can be a service city. As for the community (people), sister city programs Jakarta - Tokyo has managed to build brotherhood and friendship through sports and high school student and teacher exchanges.
\end{abstract}

Keywords: Sister City, Service City

\section{Pendahuluan}

Judul tulisan ini semula "25 Tahun sister city Jakarta - Tokyo". Pertanyaannya kenapa berubah menjadi " Menyongsong 25 tahun sister city Jakarta - Tokyo"?

Sesungguhnya pembentukan Kerja Sama Kota Jakarta - Tokyo dicetuskan pada bulan Mei 1986 ketika Gubernur KDKI Jakarta (Soeprapto) bertemu dengan Gubernur Tokyo Metropolitan pada saat menghadiri “The $2^{\text {nd }}$ Summit Conference of Mayor Cities of the World" di Istambul Turki ( Biro Kakda, 1993: 22) yang dalam teori Hubungan Internasional disebut "Taraf Kesepahaman" / Letter of Intens (LOI). Rencana kesepahaman membentuk Kerjasama Jakarta - Tokyo tersebut dimatangkan oleh Gubernur KDKI Jakarta (Wiyogo Admodarminto) pada saat kunjungannya ke Tokyo bulan September 1988 dengan menyodorkan draft materi kesepahaman kepada Tokyo Metropolitan Government (TMG).

Satu tahun kemudian tepatnya Oktober 1989 di Jakarta, Gubernur Jakarta - Ketua DPR Tokyo menanda tangani dokumen "Pernyataan Bersama" 
(Memorandum of Understanding ) yang memuat rumusan kerjasama di bidang manajemen perkotaan, kebudayaan, kesenian, olahraga serta bidang- bidang lainnya yang diperlukan oleh kedua belah pihak. Dengan ditandatanganinya MOU tersebut, resmilah Jakarta-Tokyo sebagai kota bersaudara (Sister City). Jadi, secara hukum administrasi pembentukan sister city Jakarta - Tokyo adalah pada tahun 1989 yakni pada saat ditanda tangani "Pernyataan Bersama" (MOU) sister city Jakarta - Tokyo di Jakarta. Itulah sebabnya judul tulisan ini menjadi “ Menyongsong 25 tahun Sister City Jakarta - Tokyo", artinya ada tambahan kata "Menyongsong".

\section{Permasalahan}

Seperempat abad bukanlah usia yang muda lagi, tetapi sudah menanjak dewasa sehingga pantaslah dipertanyakan secara kritis apa manfaat Sister City Jakarta-Tokyo atau dengan perkataan lain apakah Sister City Jakarta-Tokyo dapat membangun wawasan internasional warga Jakarta? Dan apakah sudah terbangun persahabatan warga Jakarta-Tokyo? Dan dari sisi akademis (perguruan tinggi), seperti Fakultas Ilmu Sosial dan Politik (FISIP) Jurusan Hubungan Internasional, apakah proses pembentukan Sister City Jakarta-Tokyo dapat dijadikan salah satu kurikulum studi ? Sedangkan bagi aparat Pemerintah Provinsi DKI Jakarta, apakah Sister City Jakarta-Tokyo dapat merubah mental aparatnya sebagai pelayan masyarakat yang bertaraf internasional dengan kata lain apakah sister city Jakarta Tokyo dapat menjadikan Jakarta sebagai service city?

Tulisan ini dimaksudkan untuk menjelaskan bagaimana cara terbentuknya sister city, apa manfaat dan kendala yang ditemukan dalam melaksanakan program sister city yang pada akhirnya harapan apa yang diinginkan dari kerja sama sister city Jakarta - Tokyo.

\section{Pembahasan}

Istilah sister city cooperation sudah ada sejak abad XII ( Ensiklopedia Americana, 1970 : 756 ). Pada abad itu, di Jerman terdapat kota pusat perdagangan (pusat perdagangan Jerman terbesar), yakni kota Bremen, Hamburg, yang berdiri secara independen. Menyadari pertumbuhan perdagangan yang begitu pesat, kota-kota ini pada abad berikutnya mengelompokan diri menjadi satu grup. Grup ini kemudian sangat terkenal dengan sebutan "Hanscatic League" yang telah beranggotakan 70 ( tujuh puluh) kota. Pada masa itu kerjasama antarkota belum sepopuler yang sekarang dan belum pula melintasi batas - batas Negara. Namun, demikian apa yang terjadi pada abad ke XII ini dapat dicatat sebagai "cikal bakal" proses sejarah pembentukan kerjasama antarkota yang lebih terkenal dengan sister province dan sister city cooperation. Istilah sister city, ada juga yang 
menyebut Brother Sister (BRO Sis) yang dipopulerkan oleh Biro KDH dan KSLN Setda provinsi DKI Jakarta ( 2009 : 19)

Dari uraian di atas dapat dilihat bahwa proses pembentukan "Hanscatic League" ternyata pemicunya (trigger) adalah kebutuhan (need) perdagangan dari kota- kota itu sendiri artinya faktor pendorongnya adalah pertumbuhan ekonomi di masing- masing kota.

Dwight Eisenhower, (Kotapradja, 1982 : 85) memperkenalkan konsep People to People relationship ( $\mathrm{P}$ to $\mathrm{P}$ ), konsep ini kemudian menjadi cikal bakal kerja sama antarmasyarakat (antarkota) melintasi batas - batas Negara. Jadi konsep ini semata-mata bermaksud memaksimalkan hubungan antar anggota masyarakat diseluruh pelosok dunia agar tercipta dan terpelihara perdamaian. Itulah sebabnya konsep ini semakin lama semakin berkembang, artinya dari semula konsep diplomasi dari rakyat, untuk rakyat, konsep Eisenhower meningkat dari masyarakat secara mikro menjadi makro yaitu antar kota dengan kota. Konsep inilah yang dikenal dengan city to city affiliation. Dengan konsep ini diharapkan dapat meredam konflik (pertentangan) politik yang tidak terselesaikan di meja perundingan yang sekaligus menjamin percepatan perdamaian.

Lebih tegas Eisenhower mengatakan : "Program persahabatan antar kota adalah sumber yang penting dari perundingan- perundingan antar pemerintahan agar rakyat sendiri menyatakan keinginannya untuk menciptakan persahabatan, kemauan baik dan kerja sama demi terciptanya dunia yang lebih baik untuk semua orang" ( Kotapraja, 1982 : 86). Perkembangan kerja sama province maupun kerja sama kota tersebut dapat diklasifikasikan menjadi kerjasama Government to Government ( $G$ to $G$ ), kerja sama Government to People ( $G$ to P), kerja sama People to Government ( $P$ to $G$ ), dan People to People ( $P$ to P). Jadi dari bentuk kerjasama tersebut dapat dikatakan sebagai ukuran berhasil atau tidaknya kerja sama sister city itu, adalah sejauh mana telah terselenggaranya kerja sama People to People ( $\mathrm{P}$ to $\mathrm{P}$ ) . Bila ini sudah berjalan, maka kedua kota itu merupakan kota bersaudara (friendship) yang sudah melibatkan pemangku kepentingan (stakeholder) kedua kota, atau kota yang sudah mewujudkan keinginan adanya perdamaian persaudaraan diantara warga masyarakat kedua kota/ province.

\section{Faktor Pendorong Kerjasama Sister City}

Secara teori, faktor utama pendorong terbentuknya sister city adalah "kebutuhan (need) bukan keinginan (wants)" (Witarsa Tambunan, Tesis : 2000). Hal ini mendapat tekanan karena apabila kedua kota (city) itu saling membutuhkan maka hubungan yang terbentuk itu lebih abadi bila dibandingkan berdasarkan keinginan (wants), karena bila keinginan yang menjadi dasar kerja sama dikuatirkan apabila keinginan kedua kota tercapai maka hubungannya menjadi bersifat sementara (temporer) dan cenderung bubar. 
Jakarta sebagai kota (city), menghadapi tantangan dalam upaya memenuhi kebutuhan pelayanan kepada masyarakat. Ternyata di satu sisi pemprov DKI Jakarta berhadapan dengan keterbatasan, seperti luas wilayah yang relatif kecil, jumlah keuangan daerah yang terbatas, sumber daya manusia yang minim membutuhkan peningkatan serta kewenangan. Sedangkan di sisi lain perkembangan aktivitas dan kehidupan masyarakat semakin pesat seiring dengan semakin derasnya arus migrasi ke Jakarta dan bertambahnya permintaan masyarakat atas pelayanan yang baik, sejalan dengan adanya peningkatan kesejahteraan masyarakat.

Pengaruh globalisasi dapat juga disebabkan sebagai faktor pendorong kerja sama sister city, era globalisasi didukung dengan kemajuan IPTEK sebagai penyebaran informasi dapat terjadi secara cepat, membuat masyarakat dunia kian dekat satu sama lain. Faktor jarak tidak lagi menjadi kendala untuk mewujudkan komunikasi yang intensif dan mendorong terwujudnya hubungan persahabatan antar bangsa dan diplomasi internasional yang semakin berkembang dalam bentuk kerja sama multilateral, regional dan bilateral yang saling menunjang. Bagi pemerintah daerah (kota), faktor dukungan pemerintah pusat terhadap penyelenggaraan kerja sama sister city sangatlah diperlukan sebagaimana diatur oleh UU No. 32 tahun 2004 tentang Otonomi Daerah.

Pasal 195 UU No. 32 Tahun 2004 memberikan kedudukan terhormat dan penting bagi kota dalam menyelenggarakan kerjasama antar daerah dalam negeri yang saling menguntungkan. Sedangkan UU No. 37 Tahun 1999 tentang Hubungan Luar Negeri, UU No. 24 Tahun 1999 tentang Perjanjian Internasional, Permendagri No. 1 Tahun 1992 tentang Penyelenggaran Hubungan dan Kerjasama di Luar Negeri di jajaran Departemen Dalam Negeri, dan Surat Edaran Mendagri No. 193/1652/PUOD tentang Cara Pembentukan Hubungan Kerjasama Kota, serta Peraturan Pemerintah No. 09/A/KP/XII/2006/01 tentang Panduan Umum Tata Cara Hubungan Dan Kerjasama Luar Negeri Oleh Pemerintah Daerah memberi kewenangan pemerintah kota untuk melakukan kerja sama dengan lembaga /badan diluar negeri telah menjadi kewenangan daerah otonom. Itulah sebabnya pemerintah provinsi DKI Jakarta sebagai ibu kota Negara yang sah diberi kewenangan oleh pemerintah pusat untuk menyelenggarakan kerja sama sister city terus mengembangkan program kemitraan, baik untuk tujuan peningkatan hubungan persahabatan, maupun dalam upaya meningkatkan kinerja pelayanan Jakarta.

Dari uraian diatas dapat dikatakan bahwa faktor pendorong terbentuknya kerja sama Jakarta - Tokyo adalah "kebutuhan yang sama" yakni adanya keinginan dua kota untuk bersahabat yang ditandai dengan bertemunya kedua Gubernur Jakarta - Tokyo, pada bulan Mei 1986 pada "The Second Summit Conference of Mayor Cities of The World" di Istambul Turki. 


\section{Proses Pembentukan Kerjasama Sister City}

Proses pembentukan kerja sama sister city dilakukan dengan beberapa tahapan, tahapan pertama adalah perencanaan, persetujuan DPR, pengusulan, negosiasi dan penanda tanganan.

Pada tahap perencanaan ini, diprogramkan secara matang bidang- bidang yang akan dikerjasamakan dalam suatu program bersama yang mencerminkan secara jelas kegiatan- kegiatan yang perlu dilaksanakan dalam jangka waktu pelaksanaan, kontribusi biaya dari masing-masing dalam jangka waktu yang diperlukan bagi program kegiatan yang di kerjasamakan. Pengawasan program tersebut terutama diluar daerah dan instansi vertikal. Disamping itu disiapkan pula rancangan naskah Memorandum of Understanding (MOU) dari kedua belah pihak pemerintah kota yang melakukan kerjasama.

Tahap persetujuan DPRD, disini rencana pembentukan hubungan kerja sama yang akan dilaksanakan oleh pemerintah kota diperlukan persetujuan DPRD tingkat atasannya, yang dituangkan dalam bentuk keputusan dewan. Jadi rencana pembentukan hubungan kerjasama serta bidang-bidang yang hendak dilaksanakan perlu mendapat persetujuan DPRD yang bersangkutan.

Selanjutnya tahap negosiasi, pada tahapan ini hasil pembahasan ditingkat pemerintah pusat mengenai konsep rancangan kerja sama (MOU), akan disampaikan kembali kepada pemerintah daerah/kota dalam negeri untuk dikonfirmasikan Draft MOU serta bidang-bidangnya, jika tidak ada masalah akan disampaikan kepada pemda/kota luar negeri untuk dibuat kesepakatan bersama.

Akhirnya dari tahapan proses pembentukan kerja sama sister city adalah penanda tanganan. Kegiatan penanda tanganan dilakukan setelah rancangan program kerjasama disepakati oleh kedua belah pihak. Penanda tanganannya dapat dilaksanakan setelah pejabat yang ditunjuk untuk menanda tangani masalah tersebut memperoleh surat kuasa penuh dari pemerintah pusat, contoh, menteri luar negeri, memorandum yang telah ditanda tangani tersebut akan menjadi dasar hukum dari hubungan kerjasama.

Dari tahapan tersebut diatas apabila dicermati dapat dikatakan bahwa proses pembentukan kerja sama sister city Jakarta - Tokyo yang mengacu pada surat edaran mendagri No.193/ 1652/ PUOD, prosesnya berbelit- belit dan melibatkan banyak instansi dan memerlukan waktu yang cukup lama. Hal ini terjadi karena surat edaran mendagri tersebut masih menggunakan UU No. 5 tahun 1974 tentang Pokok- Pokok Pemerintah Daerah, dimana daerah itu belum otonom sebagaimana yang diatur oleh UU No.32 tahun 2004 tentang otonomi daerah. Pada UU No. 5 tahun 1974 masih dikenal pemerintah tingkat I dan pemerintah tingkat II, demikian juga DPRD nya ada DPRD tingkat I dan DPRD tingkat II. Disamping itu peranan pemerintah pusat (Depdagri , Deplu dan Bakin ) cukup dominan dalam pembentukan kerjasama sister city. Berbeda dengan proses pembentukan kerja 
sama sister city setelah di berlakukannya UU Otonomi Daerah, dimana proses pembentukan kerjasama sister city relatif mudah dan tidak berbelit- belit.

Proses Skema Pengusulan Dan Pembentukan Sister City.

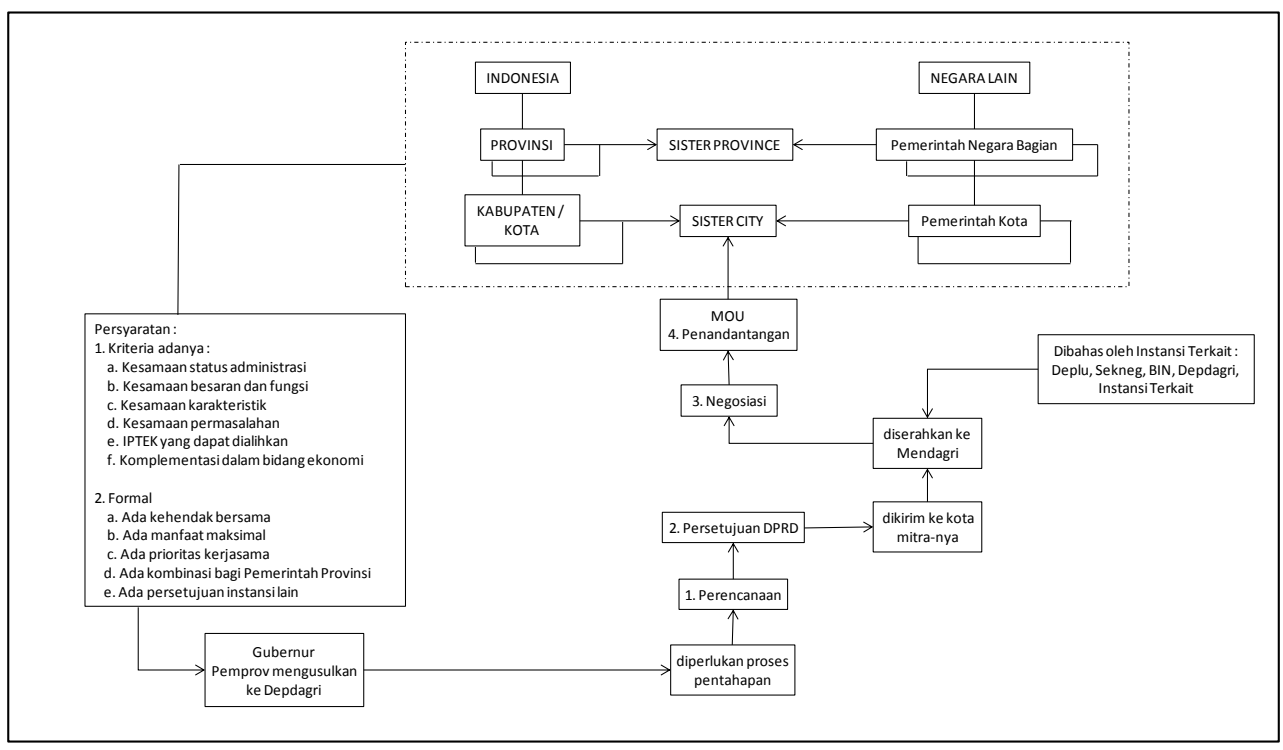

\section{Pelaksanaan Program Kerjasama}

Pada saat kunjungan Gubernur KDKI Jakarta Wiyogo Admodarminto ke Tokyo tanggal 11 April 1990 telah ditanda tangani Pernyataan Bersama (MOU) Jakarta- Tokyo program Tahun 1993/1994 (Biro Kakda, 1993 : 22) sebagai berikut : Kunjungan timbal balik tim studi banding bidang administrasi perkotaan, Pertandingan sepak bola persahabatan antar tim tingkat SLTA, Studi banding bidang ketenagakerjaan khususnya pelatihan para pelatih (Training of Trainers) pada BLK, Kunjungan dan penerimaan peserta pendidik bidang lingkungan hidup, dan Kunjungan timbal balik tim studi banding masalah lingkungan hidup.

Selanjutnya gubernur KDKI Jakarta Surjadi Soedirdja ke Tokyo pada tanggal 9 April 1993, menanda tangani program - program pertukaran kegiatan yang memuat 14 butir kegiatan: Saling menerima pejabat administrasi kedua kota, Pengiriman tim studi banding lingkungan hidup Tokyo ke Jakarta, Pengiriman instruktur latihan kejuruan Tokyo ke Jakarta, Pengiriman insinyur konstruksi bangunan Tokyo ke Jakarta, Penerimaan tim studi banding peternakan Tokyo ke Jakarta, Penerimaan insinyur pembangunan perumahan Jakarta di Tokyo, Penerimaan tim studi banding air minum Jakarta di Tokyo, Penerimaan tim sepak bola SLTA Jakarta di Tokyo, Penerimaan tim perundingan program pertukaran Tokyo ke Jakarta, Pengiriman tim penanda tanganan program pertukaran Tokyo ke Jakarta, Saling mengirim siswa - siswi SLA dan pengiriman guru SLA di Tokyo, 
Kerja sama Jakarta terhadap suatu pemerataan karya seni anak- anak sekolah yang disponsori oleh kota metropolitan Tokyo, Penerimaan peserta pelatihan kejuruan Jakarta di Tokyo dan pengiriman tim perundinga pendahuluan pelatihan kejuruan Tokyo ke Jakarta, dan Penerimaan peserta pelatihan Jakarta di Tokyo untuk mengikuti program latihan teknik luar negeri yang diselenggarakan oleh kota metropolitan Tokyo (Biro Kakda, 1993 : 23) .

Bila dilihat program kerjasama Jakarta - Tokyo tersebut di atas ada dua catatan penting, pertama bahwa program kerja tahun 1990 dan 1993 (Biro Kakda, 1993 : 22), menunjukkan bahwa dua gubernur DKI Jakarta Wiyogo Atmodarminto (1987 - 1992) dan Suryadi Soerdirdja (1992- 1997) mempunyai perhatian (concern) terhadap hubungan sister city Jakarta - Tokyo. Kedua, dilihat dari materi programnya, lebih menekankan pada peningkatan kualitas SDM aparat pemerintahan kota masing-masing, seperti pengiriman study banding administrasi perkotaan, lingkungan hidup, dan membangun sikap bersahabat masyarakat (community) kedua kota (seperti : pertandingan sepak bola, pengiriman siswa/i SLA dan guru). Oleh karena itu, dilihat dari dua hal tersebut di atas, maka dapat dikatakan kerjasama sister city Jakarta - Tokyo telah membawa manfaat bagi kedua kota bersaudara tersebut.

Demikian juga, dua gubernur berikutnya Soetiyoso (1997 - 2007) dan Fauzi Bowo (2007 - 2012) dalam program sister city Jakarta - Tokyo mempunyai perhatian yang sama. Hal ini ditandai dengan ditetapkannya tiap tahun anggaran program kerjasama Jakarta - Tokyo dalam APBD. Perbedaannya di masa Gubernur Fauzi Bowo, kegiatan program Kerjasama Sister City Jakarta - Tokyo dikembangkan (diperluas) dengan kota-kota sister city lainnya seperti pelaksanaan Tokyo Internasional Youth Football Tournament (U-14) pada tahun 2009. Program ini semula merupakan pertandingan sepakbola antara Jakarta - Tokyo, tapi Gubernur Tokyo Mr. Ishihara mengundang 10 kota mitra (Biro Kakda, 2009 : 14).

\section{Manfaat Kerjasama}

Untuk mengukur seberapa besar manfaat kerja sama Jakarta - Tokyo terhadap pembangunan Pemerintah Provinsi DKI Jakarta dan masyarakat Jakarta itu sendiri perlu kehati-hatian sebab bila kegiatan kerja sama ditinjau dari manajemen kebijakan (manajemen publik) tentu kurang "pas" karena manajemen publik melihat/ evaluasi suatu program sampai ke tingkat out come dan value added. Sedangkan program Kerja Sama Jakarta - Tokyo melihatnya dari proses pengambilan keputusan kebijakan yakni input - proses - out put artinya yang dilihat adalah "prosesnya", jadi program kegiatannya berhenti pada "out put" (terlaksana).

Disamping itu mengukur program Kerja Sama Jakarta - Tokyo secara kuantitatif adalah sulit. Sebab filosofi kerja sama sister city mengandung makna 
nilai persahabatan dan peningkatan saling pengertian antar warga kota $(\mathrm{P}-\mathrm{P}$ ) tidak hanya antar institusi yang bekerja sama di lingkungan pemerintah kota masing - masing. Itulah sebabnya program kerja sama Jakarta - Tokyo tidak hanya berkaitan dengan aspek teknis, tetapi juga aspek rasio kultural.

Kesulitan lain untuk mengukur manfaat kerja sama dengan tolak ukur kuantitatif, misalnya manfaat kunjungan pejabat pemerintah provinsi DKI Jakarta ke Tokyo Metropolitan Government ( TMG) untuk studi banding tentang tata cara penyelenggaraan pemerintahan manajemen perkotaan. Dalam kasus ini sulit mengukur secara kuantitatif artinya mengukur secara material, melainkan harus dilihat dari sudut manfaatnya berupa wawasan pejabat yang bersangkutan, yang kalau diterapkan akan memberikan pengaruh yang sangat positif.

Manfaat kerja sama sister city Jakarta - Tokyo, tidak terlepas dari pengaruh globalisasi dewasa ini, dan komunikasi serta interaksi juga saling ketergantungan ( interpedency ) di antara Negara dan kota- kota di dunia yang diwujudkan dalam bentuk kerja sama cenderung semakin meningkat. Fenomena ini merupakan pencerminan daripada kepentingan nasional dan daerah yang terdapat di masing - masing Negara atau kota tersebut. Jakarta sebagai ibukota Negara yang mempunyai visi sejajar dengan kota - kota diluar negeri sudah barang tentu membuka diri dengan kota - kota diluar negeri dengan harapan melalui kerja sama kota sister city ( Brother City ) terjalin persaudaraan diantara masyarakatnya (people) dan bila itu sudah tercipta, maka terbangunlah cakrawala atau wawasan kota dunia.

Kota yang berwawasan kota dunia memiliki service city yang bertarap internasional. Dalam rangka menjadikan kota Jakarta sebagai service city, Pemerintah Provinsi DKI Jakarta berusaha terus menerus meningkatkan kualitas SDM (aparatnya) dalam rangka pelayanan prima. Pelayanan prima disini dimaksudkan aparat kota Jakarta telah memiliki kompetensi (knowledge, skill dan attitude), jadi aparat sebagai pelayan masyarakat dituntut memiliki pengetahuan dan kemampuan yang sesuai dimana dia bertugas artinya jangan sampai terjadi yang menangani bidang kepegawaian (BKD) dan bidang perencanaan pembangunan (Bappeda) seorang medis (dokter) . Disamping kedua hal tersebut (pengetahuan dan kemampuan), masalah sikap (mental) aparat perlu mendapat perhatian artinya aparat pemprov DKI Jakarta menyadari bahwa dia adalah pelayan masyakat bukan pejabat yang dilayani.

Service City menuntut kesiapan perubahan sikap (attitude change) dari setiap aparat pemprov DKI Jakarta, sehingga kualitas (mutu) pelayanan yang diberikan kepada masyarakat (pelanggan) memuaskan dan dapat memenuhi standar internasional, dengan demikian masyarakat internasional yang memerlukan pelayanan dari pemprov DKI Jakarta terlayani. Seperti pelayanan yang diberikan pemprov DKI Jakarta kepada warga negara asing misalnya pencatatan perkawinan (akte nikah) dan pencatatan lahir (akte lahir) sudah 
memenuhi standart internasional, demikian juga pelayanan kepada warga Jakarta sendiri dalam program sister city Jakarta-Tokyo misalnya pengiriman tenaga kerja Jakarta ke Tokyo untuk mengikuti 0n Job Training (0JT) atau magang di industri (pabrik) mendapat antusias yang sangat tinggi. Semua itu dilakukan dalam rangka menjadikan Jakarta sebagai service city.

Hal ini perlu dilakukan selain sarana untuk mempromosikan dan meningkatkan citra positif Kota Jakarta dimata dunia, khususnya dimata masyarakat Kota Tokyo, juga sebagai sarana dan upaya untuk meningkatkan kapasitas aparat Pemerintah Provinsi DKI Jakarta dan masyarakat kota Jakarta pada umumnya, melalui partisipasi dan keikut sertaan pada berbagai program pertukaran, forum/seminar internasional dan berbagai program pelatihan yang ditawarkan oleh berbagai instansi di TMG. Jadi dapat dikatakan program kerja sama sister city Jakarta - Tokyo telah memberikan manfaat baik secara langsung dan tidak langsung bagi peningkatan citra positif kota Jakarta serta bagi peningkatan kapasitas dan kinerja aparat pemerintah provinsi DKI Jakarta dan masyarakat kota Jakarta pada umumnya . Juga melalui program sister city Jakarta - Tokyo, service city yang dilakukan oleh pemprov DKI Jakarta sudah dapat dirasakan .

\section{Kendala}

Untuk melihat kendala apa yang dihadapi dalam pelaksanaan program kerja sama sister city Jakarta - Tokyo dapat dibagi menjadi dua, yakni secara internal dan eksternal. Kendala internal, pertama kualitas SDM. Dalam hal ini sumber daya aparat perencana dan pelaksana pada unit yang menangani urusan luar negeri di lingkungan pemerintah provinsi DKI Jakarta belum sesuai dengan kompetensi, misalnya : sistem pemerintahan di luar negeri; pola - pola hubungan antar pemerintah daerah di luar negeri dengan dunia usaha; prinsip - prinsip dan prioritas kebijaksanaan bantuan luar negeri; informasi lengkap tentang faktor kebudayaan pariwisata, pendidikan dan hal- hal yang dimiliki oleh TMG yang memiliki kemungkinan untuk di kerja samakan dengan Jakarta sulit didapat karena kurangnya informasi disebabkan hambatan komunikasi (kurangnya staf yang menguasai bahasa Inggris).

Kendala kedua secara internal adalah masalah sinkronisasi program sister city Jakarta - Tokyo yang kaitannya dengan anggaran. Masalah sulitnya proses anggaran sering kali membawa kendala tersendiri artinya antara penyusunan rancangan anggaran yang diperlukan untuk tahun kegiatan tidak selaras, sehinggah dalam pelaksanaan terkesan rancangannya bersifat dadakan tidak terencana dengan baik.

Adapun kendala eksternal, yang pertama adalah masalah perbedaan organisasi yang menangani program sister city Jakarta - Tokyo. Dalam hal ini unit 
atau lembaga yang menangani kerja sama Jakarta - Tokyo di Jakarta ditangani oleh semua biro kerja sama antar kota dan daerah yang selanjutnya berubah menjadi biro KDH dan KSLN Setda Provinsi DKI Jakarta, sedangkan di Tokyo Metropolitan Government (TMG) ditangani Biro Pariwisata. Sehingga masalah ini oleh Biro Kakda dianggap serius sebagai suatu kendala dalam menangani kerja sama. ( $2003: 90$ )

Adapun kendala kedua secara eksternal adalah masalah kemitraan pemerintah kota. Hal ini di jadikan salah satu kendala karena pergantian pemimpin kota (gubernur) karena komitmennya tidak sama dengan pendahulunya sehinggah mengakibatkan terganggunya hubungan kota kembar ( sister city) yang telah disepakati oleh gubernur terdahulu.

Sedangkan kendala ketiga, menyangkut sistem pemerintah daerah dan konstelasi politik lokal. Apabila dilihat kebelakang ( flash back) bahkan filosofi sister city adalah "persaudaraan" ini berarti kerja sama sister city itu terbebas dari pengaruh politik (percaturan politik lokal) yang terjadi justru DPRD yang dipilih langsung oleh rakyat komitmennya terhadap kerja sama sister city tidak seserius seperti gubernur. Hal ini dapat dilihat dengan perubahan Biro Kakda (Biro Kerjasama Daerah ) menjadi Biro KDH dan KSLN (Biro Kepala Daerah dan Kerja Sama Luar Negeri).

Biro KDH dan KSLN sebagai instansi yang menangani sister City mengatakan sesungguhnya kendala yang dihadapi dalam melaksanakan Kerja Sama Sister City Jakarta - Tokyo hampir tidak ditemukan kendala dan hambatan. Semua program kegiatan yang disepakati, kecuali ketika terjadinya krisis ekonomi yang melanda Jepang beberapa waktu yang lalu, yang pada gilirannya melahirkan sejumlah implikasi terhadap kebijaksanaan umum, pengalokasian anggaran, termasuk untuk program kerjasama kota (Biro Kakda, 2003 : h. 29).

\section{Kesimpulan}

1. Manfaat sister city Jakarta - Tokyo, secara kuantitatif sulit diukur tapi secara kualitatif dapat dirasakan manfaatnya oleh masyarakat kota Jakarta dan Tokyo. Di samping itu, sister city Jakarta - Tokyo secara langsung maupun tidak langsung dapat membangun citra positif kota Jakarta sebagai kota internasional.

2. Bahwa visi Jakarta: "Menyejajarkan Jakarta dengan kota dunia", berarti kota Jakarta membuka diri dengan kota-kota di luar negeri, sama dengan filosofi sister city yaitu kota bersahabat dengan demikian melalui sister city Jakarta Tokyo sudah terbangun persahabatan masyarakat kedua kota.

3. Pembentukan kerjasama sister city Jakarta - Tokyo melalui proses yang panjang dan bertahap yang dimulai dari perencanaan, persetujuan DPR, pengusulan, negosiasi, dan penanda tanganan, serta keterlibatan beberapa 
instansi. Proses pembentukan sister city tersebut di dunia akademis (Perguruan Tinggi) utamanya FISIP jurusan HI tidak diperoleh/ diajarkan sementara mahasiswa/i yang kuliah di jurusan HI kelak bila bekerja di Pemprov / Kabupaten/Kota belum berpengalaman dalam masalah pembentukan sister city.

4. Dalam rangka menjadikan kota Jakarta sebagai service city melalui sister city Jakarta - Tokyo, Pemprov DKI Jakarta secara rutin dan berkala mengirimkan aparatnya ke Tokyo untuk mengikuti program pertukaran, seminar internasional, dan berbagai program pelatihan sehingga aparat yang dikirim ke Tokyo tersebut mengalami perubahan sikap maupun wawasan internasional.

\section{Saran}

1. Untuk menjadikan Jakarta sebagai kota internasional, tentunya program sister city, yang sudah ada perlu ditingkatkan dan diperluas dengan kota-kota luar negeri.

2. Agar terjalin persahabatan masyarakat Jakarta - Tokyo, perlu dibentuk satu lembaga (sebagai instrumen) yang bisa membuat satu program bersama antara masyarakat (People to People).

3. Proses pembentukan sister city, mulai dari tahapan-tahapan, skema, serta instansi-instansi yang terkait dalam menangani sister city ini perlu disosialisasikan ke dunia akademis (Perguruan Tinggi) utamanya bagi mahasiswa jurusan Hubungan Internasional. Hal ini sebagai implikasi diberlakukannya UU No. 32 Tahun 2004.

4. Untuk meningkatkan wawasan internasional aparat Pemprov DKI Jakarta, perlu diagendakan pengiriman aparatnya secara bergilir dan berkesinambungan untuk mengikuti pelatihan / seminar dan magang di kota Tokyo, tentunya diikuti dengan anggaran (APBD).

5. Kiranya Pemerintah Provinsi DKI Jakarta mendorong keterlibatan warga masyarakat kedua kota, artinya programnya dapat membangun karakter bangsa seperti peningkatan disiplin, harga diri (egoism), dan membangun rasa keadilan sehingga Program Kerja Sama Jakarta - Tokyo dapat meningkatkan kesejahteraan masyarakat, dengan demikian salah satu tugas guberur untuk meningkatkan kesejahteraan masyarakat dapat diwujudkan.

\section{Daftar Pustaka}

Biro Kakda. 1993. Hubungan Kemitraan LN Pemerintah DKI Jakarta. Jakarta: Pemda DKI Jakarta. 
Biro KDH dan KSLN. 2009. Dokumentasi Pelaksanaan KSLN. Jakarta: Pemprov DKI Jakarta.

Soedirdja, Surjadi. 1997. Kiat-Kiat Membangun Kota Jakarta. Jakarta: PT. Dian Rakyat.

Soeprapto. 1987. Catatan Masa Bhakti Gubernur KDKI Jakarta 1982 - 1987. Jakarta: Pemda DKI Jakarta. 